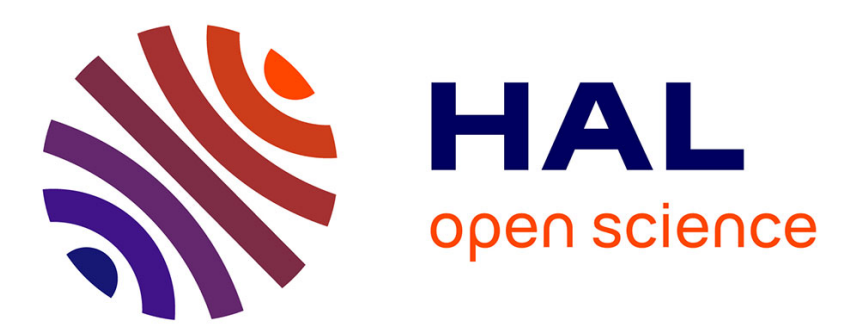

\title{
Thermal response of DP600 dual-phase steel under ultrasonic fatigue loading
}

Noushin Torabian, Véronique Favier, Saeed Ziaei-Rad, Justin Dirrenberger, Frédéric Adamski, Nicolas Ranc

\section{- To cite this version:}

Noushin Torabian, Véronique Favier, Saeed Ziaei-Rad, Justin Dirrenberger, Frédéric Adamski, et al.. Thermal response of DP600 dual-phase steel under ultrasonic fatigue loading. Materials Science and Engineering: A, 2016, 677, pp.97-105. 10.1016/j.msea.2016.09.025 . hal-01377599

\section{HAL Id: hal-01377599 https://hal.science/hal-01377599}

Submitted on 7 Oct 2016

HAL is a multi-disciplinary open access archive for the deposit and dissemination of scientific research documents, whether they are published or not. The documents may come from teaching and research institutions in France or abroad, or from public or private research centers.
L'archive ouverte pluridisciplinaire HAL, est destinée au dépôt et à la diffusion de documents scientifiques de niveau recherche, publiés ou non, émanant des établissements d'enseignement et de recherche français ou étrangers, des laboratoires publics ou privés. 


\title{
Thermal response of DP600 dual-phase steel under ultrasonic fatigue loading
}

\author{
Noushin Torabian ${ }^{\mathrm{a}, \mathrm{b}, *}$, Véronique Favier ${ }^{\mathrm{a}}$, Saeed Ziaei-Rad ${ }^{\mathrm{b}}$, Justin Dirrenberger ${ }^{\mathrm{a}}$, \\ Frédéric Adamski ${ }^{a}$, Nicolas Ranc ${ }^{\text {a }}$ \\ a Laboratoire PIMM, Arts et Métiers Paris Tech, CNAM, CNRS, Paris 75013, France \\ b Department of Mechanical Engineering, Isfahan University of Technology, Isfahan 84156-83111, Iran
}

Keywords:

Ultrasonic fatigue

Infrared thermography

Dual-phase steel

Ferrite

Dissipative mechanisms

Dislocations

\begin{abstract}
A B S T R A C T
The present work employed in situ infrared thermography to investigate the thermal response and dissipative mechanisms of a dual-phase steel under ultrasonic tension-compression fatigue testing. A classical thermal response occurred for stress amplitudes below 247 MPa but an abnormal thermal response was observed for stress amplitudes above $247 \mathrm{MPa}$, in that the temperature stabilized after a steep increase of up to $\sim 350^{\circ} \mathrm{C}$. The mean dissipated energy per cycle was estimated based on temperature measurements using the heat diffusion equation. The relationship between the mean dissipated energy per cycle and the stress amplitude was studied, and mechanisms related to the observed thermal response were discussed.
\end{abstract}

\section{Introduction}

An evaluation of the fatigue properties in high-cycle and recently in very-high-cycle regimes (beyond $10^{7}$ cycles) is of significant importance for researchers and industrial companies. Because of the costly and time-consuming nature of traditional fatigue-characterization experiments, several alternative approaches have been developed to carry out a rapid evaluation of fatigue properties. Since fatigue loading is an energy-dissipating process, it is accompanied by temperature variations of the material that undergoes a fatigue test. Therefore, most alternative fatigue characterization methods are based on a thermographic analysis of the material under fatigue loading. Some researchers have employed this approach as a nondestructive evaluation of materials under cyclic loadings (see, for example, the pioneer works of Stromeyer [1] and Luong [2]). Moreover, this approach has been widely used to model or predict material fatigue properties such as fatigue life or endurance limit under conventional low frequency fatigue tests [3-6].

Owing to the development of ultrasonic fatigue test systems working at very high frequencies $(20-30 \mathrm{kHz})$, it has been possible

\footnotetext{
* Corresponding author at: Laboratoire PIMM, Arts et Métiers Paris Tech, CNAM, CNRS, Paris 75013, France.

E-mail address: noushin.torabiandehkordi@ensam.eu (N. Torabian).
}

to investigate the fatigue behavior of materials up to a large number of cycles in a reasonable testing time [7,8]. Ultrasonic fatigue tests may induce a much higher temperature increase than conventional fatigue tests that use frequencies below $100 \mathrm{~Hz}$. Therefore, several research studies have been conducted on thermal measurements and calorimetric studies for metallic materials under ultrasonic fatigue loading in high- and very-high-cycle fatigue ranges. These research works can be categorized into two groups. The first category consists of studies that have used dissipation estimations to investigate the fatigue damage process and crack initiation mechanisms in very-high-cycle fatigue regimes [916]. For instance, Xue et al. [11] and Wagner et al. [12] used in situ thermography and fracture surface analysis for different steels and aluminum alloys under ultrasonic fatigue loading and showed that a correlation exists between the temperature fields in the specimen and the fatigue damage process. The second group of research works on thermal measurements under ultrasonic fatigue loading has employed thermal response of materials for the rapid estimation of their fatigue properties. Huang et al. $[17,18]$ investigated the fatigue dispersion of a titanium alloy and a low carbon steel in very-high-cycle fatigue regime using a $20-\mathrm{kHz}$ ultrasonic testing machine. They observed that a plot of the variations of mean stationary temperature increment versus stress amplitude comprised two linear curves with an intersection point. They attributed the change in slope of this plot to a change in 
dissipation mechanism from anelastic to inelastic (similar to what has been widely reported for metals under conventional low-frequency fatigue tests $[6,19])$.

In general, for both low- and high-frequency fatigue tests, the classical temperature evolution of a material that undergoes fatigue straining and damage up to failure consists of three main stages: the first stage is an initial increase at the beginning of the test, the second stage is associated with a steady-state or a slight increase and the last stage is a final sharp increase that is related to fracture initiation (see, for example, $[13,16,20]$ ). Ranc et al. [20] observed that ferritic-pearlitic C45 steel that was loaded cyclically at $20 \mathrm{kHz}$ did not follow this classical thermal response and exhibited a steep increase in temperature up to a few hundreds of degrees, which did not lead to a final rupture. Huang et al. [21] observed a similar abnormal thermal response for another ferriticpearlitic steel (A48 steel according to the French standard), which showed an unusual change in temperature increase rate without any fracture initiation. In this work, DP600 dual-phase steel was studied. This steel contains an alloyed ferritic phase as the aforementioned C45 and A48 steels, but the second phase is different as it is constituted of dispersed martensite islands instead of pearlite. The purpose of the present research is to provide further evidence of such abnormal thermal responses as, to the authors' knowledge, there is a lack of results in the literature for such complicated thermal responses of two-phase steels. We suggest that the abnormal change in thermal response is related to the deformation mechanisms in the ferritic phase, which transit from a thermally activated regime to an athermal regime.

\section{Material and experimental procedure}

Commercial dual-phase steel DP600 with the chemical composition given in Table 1 was used in this study. This ferriticmartensitic steel contains $15 \mathrm{wt} \%$ martensite and was received as sheets of $3.6 \mathrm{~mm}$ thickness. The mechanical properties of the material in the transverse direction are presented in Table 2.

Sections of material were mechanically polished and were etched by using $2 \%$ Nital solution and then were studied by optical microscope. Fig. 1 shows the material microstructure that was obtained by optical microscopy.

A piezoelectric fatigue system was used for the fatigue tests at $20 \mathrm{kHz}$. Hourglass-shaped specimens were used with the geometry shown in Fig. 2. The specimen dimensions were obtained from the analytical solution of the vibration equations to obtain a resonant vibration frequency of $20 \mathrm{kHz}$ for the specimen. In all of the tests that were carried out in this research, the specimen was loaded in tension-compression $\left(\mathrm{R}=\frac{\sigma_{\min }}{\sigma_{\max }}=-1\right)$ without cooling. All specimens were cut parallel to the transverse direction and were polished mechanically with a sequence of SiC papers (220-1200) and finally were electropolished to remove residual stresses induced by the machining and mechanical polishing. Surface profilometry analysis showed that electropolishing removes a material layer of $\sim 1.6 \mu \mathrm{m}$.

In order to measure the temperature evolution on the specimen surface during the tests, an infrared camera with a spatial resolution of $0.024 \mathrm{~mm}$ per pixel was used. The acquisition frequency was $10 \mathrm{~Hz}$. Specimens were coated with a high-temperature resistant and strongly emissive black paint to limit the errors

Table 1

DP600 chemical composition [5].

\begin{tabular}{llllllll}
\hline Alloying element & $\mathrm{Mn}$ & $\mathrm{Ni}$ & $\mathrm{Si}$ & $\mathrm{Cr}$ & $\mathrm{C}$ & $\mathrm{Al}$ & $\mathrm{Nb}$ \\
\hline \% weight & 0.933 & 0.020 & 0.213 & 0.727 & 0.0748 & 0.039 & 0.0425 \\
\hline
\end{tabular}

Table 2

Mechanical properties of DP600 steel [5].

\begin{tabular}{llll}
\hline $\begin{array}{l}\text { Young Modulus } \\
(\mathrm{GPa})\end{array}$ & $\begin{array}{l}\text { Yield strength } \\
(\mathrm{MPa})\end{array}$ & $\begin{array}{l}\text { Ultimate tensile } \\
\text { strength }(\mathrm{MPa})\end{array}$ & Elongation (\%) \\
\hline 210 & 440 & 650 & 20 \\
\hline
\end{tabular}

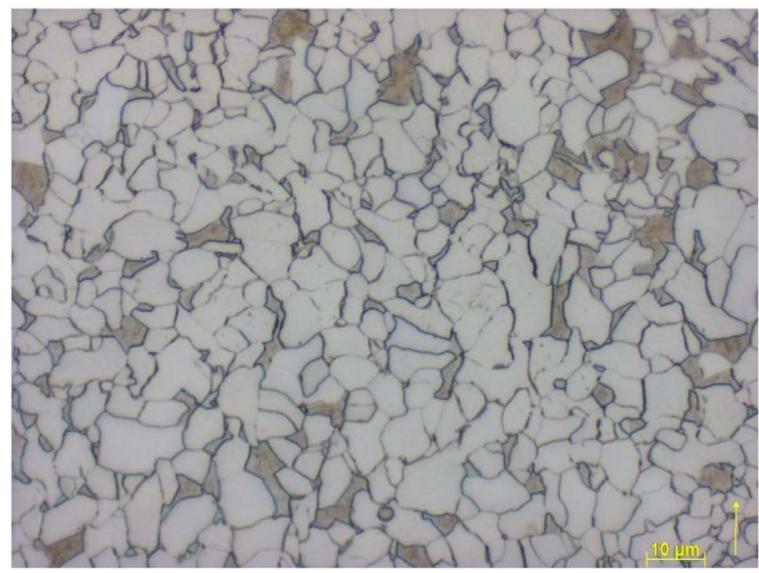

Fig. 1. Microstructure of the DP600 sample (dark grains are martensite and bright grains are ferrite).

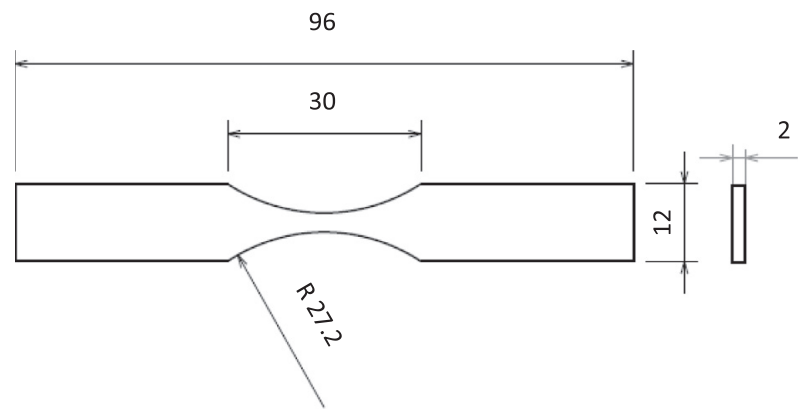

Fig. 2. Dimensions of ultrasonic fatigue test specimen ( $\mathrm{mm})$.

associated with surface emissivity.

Self-heating tests were conducted. These tests consisted of a series of cyclic loadings for the same specimen with increasing stress amplitude, as illustrated in Fig. 3. At each stress amplitude, a fatigue test was carried out up to $10^{7}$ cycles and the temperature field on the specimen surface was recorded. All testing steps were conducted at a constant stress amplitude, $\sigma_{a}$, and a constant loading frequency, f, of $20 \mathrm{kHz}$. At the end of each step, the testing machine was stopped and temperature measurements were continued for 2 min to record the temperature decrease of the specimen after stopping the test. A time gap of $\sim 10 \mathrm{~min}$ between two successive steps ensured that the specimen temperature was homogeneous and equal to the ambient temperature before starting the next loading step. Fatigue tests were repeated for three samples to ensure result reproducibility. In all cases, the temperature was measured at the center of the gauge part of the specimen in a circular area with a diameter of $\sim 1 \mathrm{~mm}$ (as shown in Fig. 4(b)). It can be supposed that the temperature is homogenous along the specimen thickness and is equal to the surface temperature. The homogeneity of temperature through the thickness can be justified by calculating the Biot number, $B i=\frac{h L_{c}}{k}$, where $h$ is the convection coefficient, $k$ represents the thermal conductivity and $L_{c}$ is the characteristic length, which is equal to the thickness in our case. This number represents the ratio of heat 


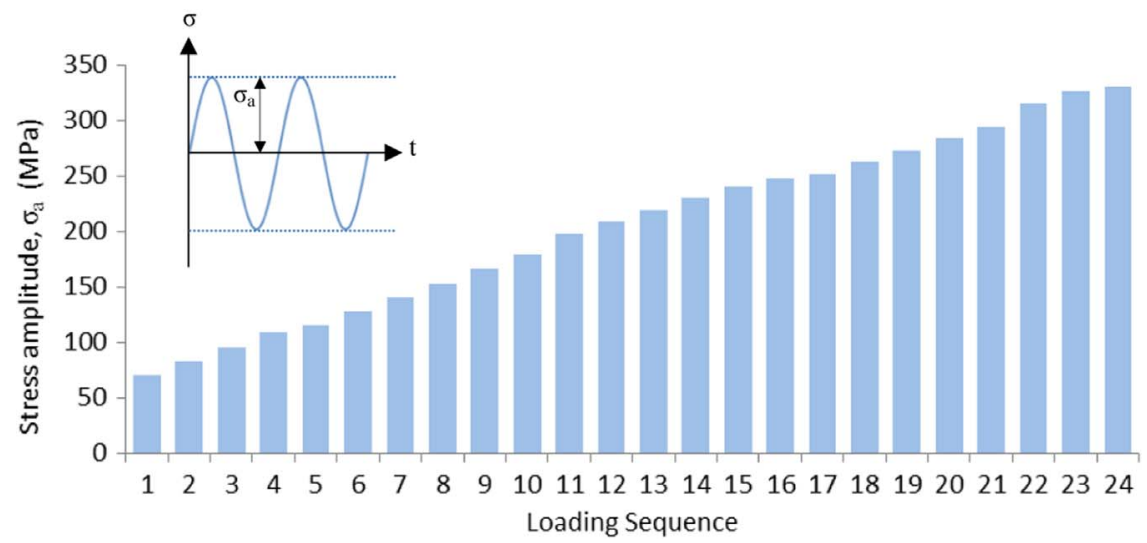

Fig. 3. Successive fatigue loadings (each block consists of $10^{7}$ cycles).

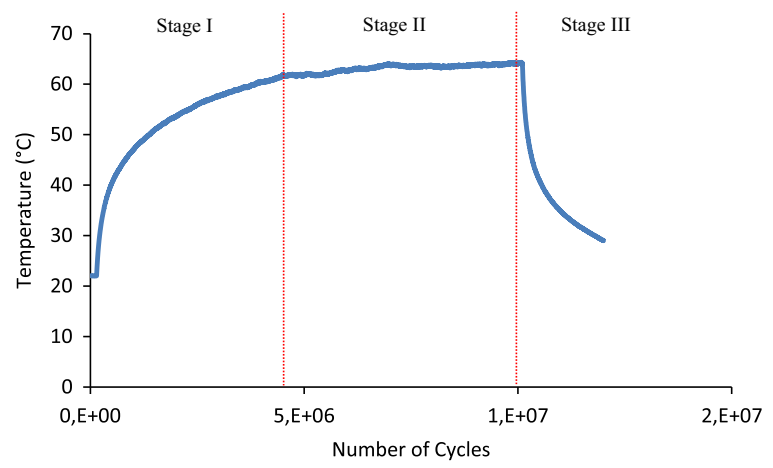

(a)

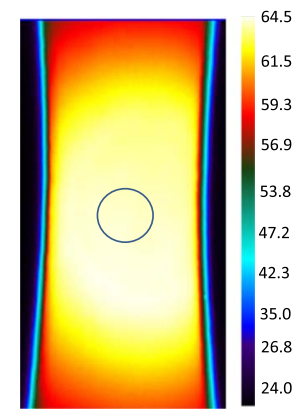

(b)

Fig. 4. Loading step with $\sigma_{a}=209 \mathrm{MPa}$ : (a) temperature evolution versus time; (b) temperature field on specimen surface at $\mathrm{N}=9.9 \times 10^{6}$ cycles (mean temperature was measured in the circular area in the center of the specimen, where the temperature is uniform).

transfer resistance inside of and at the surface of a body. Therefore, by considering $h=10 \mathrm{~W} \mathrm{~m}^{-2} \mathrm{~K}^{-1}$ for normal conditions and $k=52 \mathrm{~W} \mathrm{~m}^{-1} \mathrm{~K}^{-1}$ for DP600 steel, the Biot number will be equal to $3.8 \times 10^{-4}$. Because the Biot number remains far smaller than unity, the temperature can be assumed to be homogenous through the specimen thickness.

\section{Experimental results}

\subsection{Temperature variations during cycling}

As mentioned previously, successive steps of the fatigue tests were conducted with increasing stress amplitude and the mean temperature was registered at each step. For instance, Fig. 4 shows the mean temperature evolution during one of the loading steps and the temperature field on the specimen surface. From this figure it is clear that the mean temperature increased rapidly at the beginning of the test (Stage I) and then stabilized at a steadystate value (Stage II). The stabilization of the temperature corresponds to a balance between the mechanical energy dissipated into heat and the energy lost by convection and radiation at the specimen surface and by conduction inside the specimen. Thus, the level of the stabilized temperature is linked directly to the dissipation. Stage III shows the specimen natural cooling after stopping the test at $10^{7}$ cycles. This cooling stage occurred because of the stop in dissipation (heat source) after stopping the test, and characterizes the heat losses due to conduction and convection.

The evolutions of the mean temperature for some of the loading steps with different stress amplitudes are shown in Fig. 5. This figure shows that by increasing the stress amplitude, the mean steady-state temperature grew gradually with the same trend as shown in Fig. 4 until it reached $\sim 100{ }^{\circ} \mathrm{C}$ for the stress amplitude of $247 \mathrm{MPa}$ (Curve (a) in Fig. 5). However, by increasing the stress amplitude from $247 \mathrm{MPa}$ to $251 \mathrm{MPa}$, the temperature evolution trend changed. The temperature was below $135^{\circ} \mathrm{C}$ during the early $8 \times 10^{6}$ cycles. At $\sim 8 \times 10^{6}$ cycles, the mean temperature increased significantly, peaked at $\sim 350^{\circ} \mathrm{C}$ and then decreased slightly before it stabilized at $\sim 280{ }^{\circ} \mathrm{C}$ (Curve (b)). For the next two loading steps with stress amplitudes of $\sigma_{a}=266 \mathrm{MPa}$ and $273 \mathrm{MPa}$ (Curves (c) and (d)), the temperature elevation was far less than the previous step at $\sigma_{a}=251 \mathrm{MPa}$. Increasing the stress to $\sigma_{a}=283 \mathrm{MPa}$ (curve (e)) resulted in a significant increase in temperature with the same pattern as seen previously for $\sigma_{a}=251 \mathrm{MPa}$. These phenomena were repeated up to the specimen rupture at $\sigma_{a}=330 \mathrm{MPa}$. Indeed after the loading step with

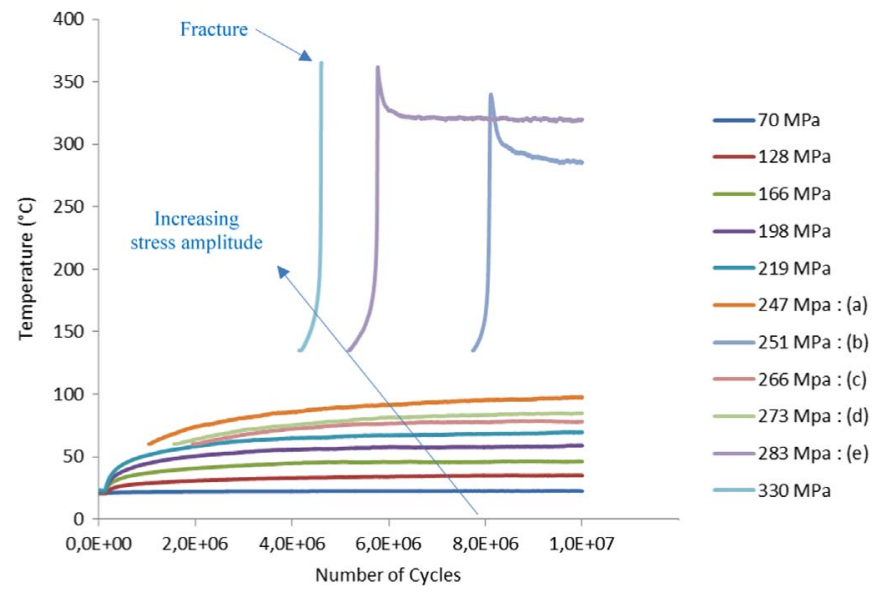

Fig. 5. Temperature evolution versus number of cycles for different stress amplitudes before stopping the tests. 


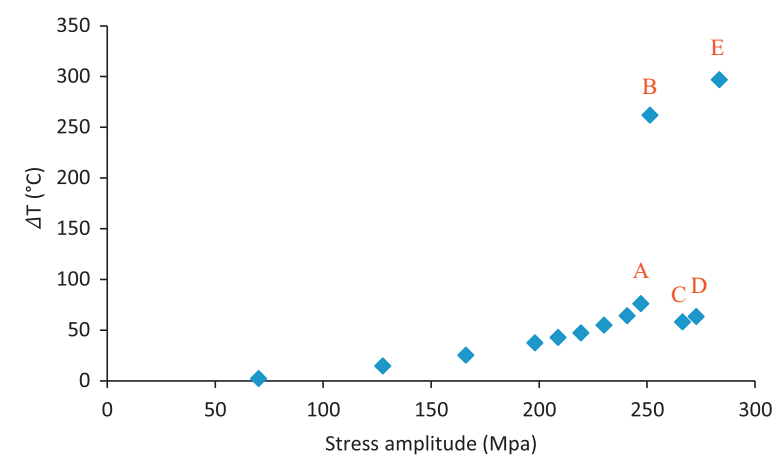

Fig. 6. Stationary mean temperature increase versus stress amplitude under ultrasonic fatigue tests for DP600 steel.

$\sigma_{a}=283 \mathrm{MPa}$ (curve (e)), an increase in stress amplitude to $300 \mathrm{MPa}$ in the following step resulted in a decrease in the temperature elevation, in the same way as that observed for $\sigma_{a}=266 \mathrm{MPa}$ and $273 \mathrm{MPa}$. However, for the sake of brevity, the results of these subsequent loading steps are not presented in Fig. 5. It should be mentioned that in Fig. 5, for the loading steps with high stress amplitudes ( $\sigma_{a} \geq 247 \mathrm{MPa}$ ), the initial parts of the temperature evolution curves are missing because the temperature was less than the minimum recordable value according the camera calibration.

\subsection{Evolution of self-heating versus stress amplitude}

For each loading step in Fig. 5, and excluding the final step in which fracture occurred, the mean steady-state temperature elevation, which is defined as $\Delta T=T_{\text {steady }}-T_{0}$, is plotted versus the stress amplitude in Fig. 6. $T_{0}$ is the initial temperature of the specimen that is recorded each time before starting the tests.

Fig. 6 shows that the temperature elevation increased gradually by increasing the stress amplitude up to a critical value, $\sigma_{c}$ (corresponding to point $A$ ). Thereafter, an increase in the stress amplitude resulted in a significant increase in temperature elevation (point B). For subsequent slight increases in stress amplitude, the temperature elevation decreased substantially (points $C$ and D) followed by another significant increase at $\sigma_{a}=283 \mathrm{MPa}$ (point E). This trend continued up to specimen rupture.

Fig. 7 shows the temperature fields on the specimen surface obtained from infrared thermography for $\sigma_{a}=\sigma_{c}=247 \mathrm{MPa}$ (point A in Fig. 6), in which the temperature field on the specimen surface is correlated with the temperature evolution during cyclic loading. This figure shows that the temperature was distributed homogenously through the specimen width with a maximum zone at the center of the gauge area. The temperature field pattern was the same for all stress amplitudes smaller than $\sigma_{c}$, with a difference only in steady-state temperature value, which increased with increasing stress amplitude. However, the temperature field was different for stress amplitudes greater than this critical stress amplitude, $\sigma_{a}>\sigma_{c}$, for which a sudden increase occurred in temperature elevation (stress amplitudes corresponding to points $\mathrm{B}$ and E, in Fig. 6). The thermographic images obtained for $\sigma_{a}=251 \mathrm{MPa}$ (corresponding to point B in Fig. 6) are presented in Fig. 8. As shown in this figure, after $7.756 \times 10^{6}$ cycles, the temperature reached locally a minimum recordable value based on the camera calibration $\left(\mathrm{T}=135^{\circ} \mathrm{C}\right)$ and then an inhomogeneous temperature zone was observed at the left side of the specimen gauge part. Afterwards, this zone propagated through the specimen with increasing the number of cycles. This observation indicates the initiation of a strong localized dissipative mechanism and a consequent creation of a high-temperature zone. Fig. 8(d) and (e) show that after the temperature peaked at $\sim 350^{\circ} \mathrm{C}$, the localized dissipation stopped and the temperature field became homogeneous through the specimen width. In other words, homogeneous dissipation occurred and temperature stabilized at a high level.

For the higher stress amplitudes (point E in Fig. 6) the same behavior was observed up to the stress value at which specimen rupture occurred. Fig. 9 depicts the temperature field for $\sigma_{a}=330 \mathrm{MPa}$ for different numbers of cycles up to rupture. Before $\mathrm{N}=4.428 \times 10^{6}$ cycles, the temperature was less than the minimum recordable value based on the camera calibration. However, after this number of cycles, an inhomogeneous temperature zone was visible near the specimen edge. This inhomogeneous zone grew rapidly up to specimen fracture, which corresponds to a maximum temperature. At this instant, the test stopped (a)

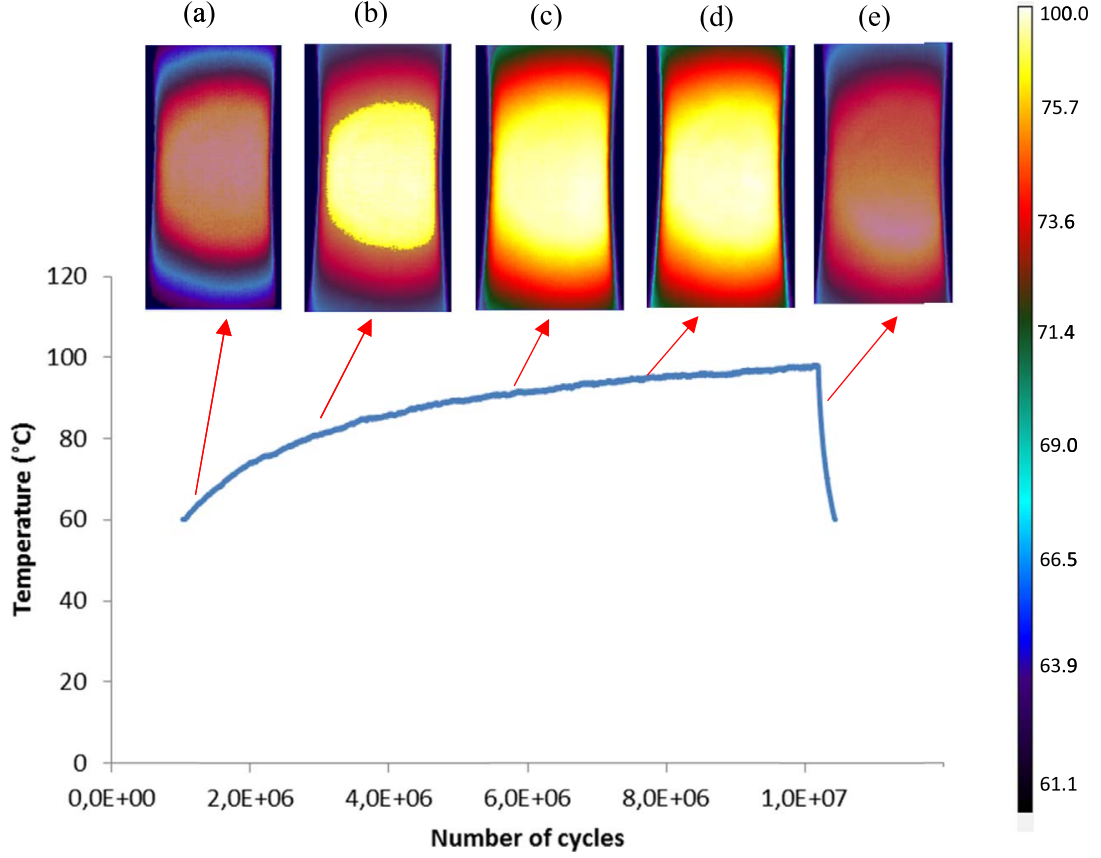

Fig. 7. Temperature fields on specimen surface during fatigue loading and after stopping the test, for $\sigma_{a}=247 \mathrm{MPa}$. 
(b)

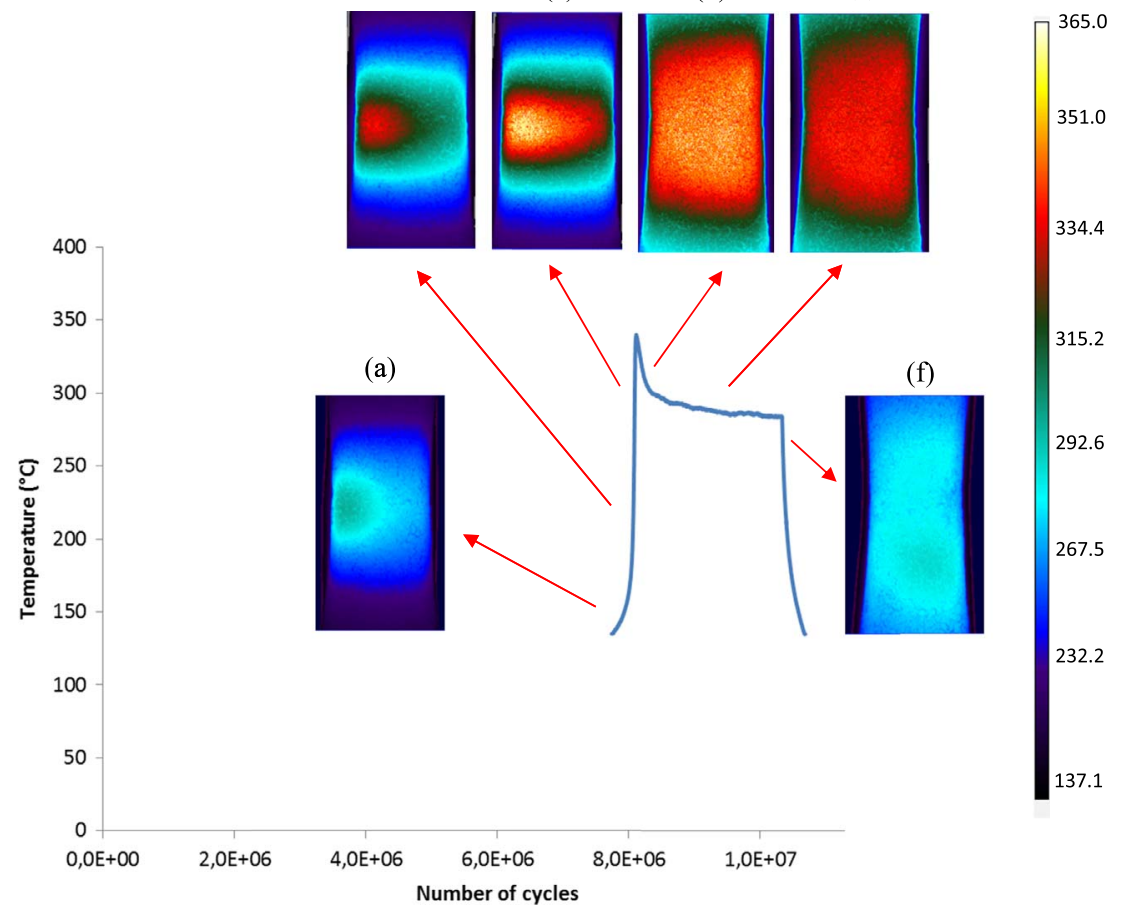

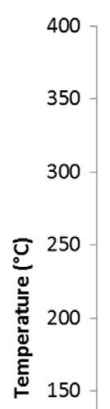

(c)

(d)
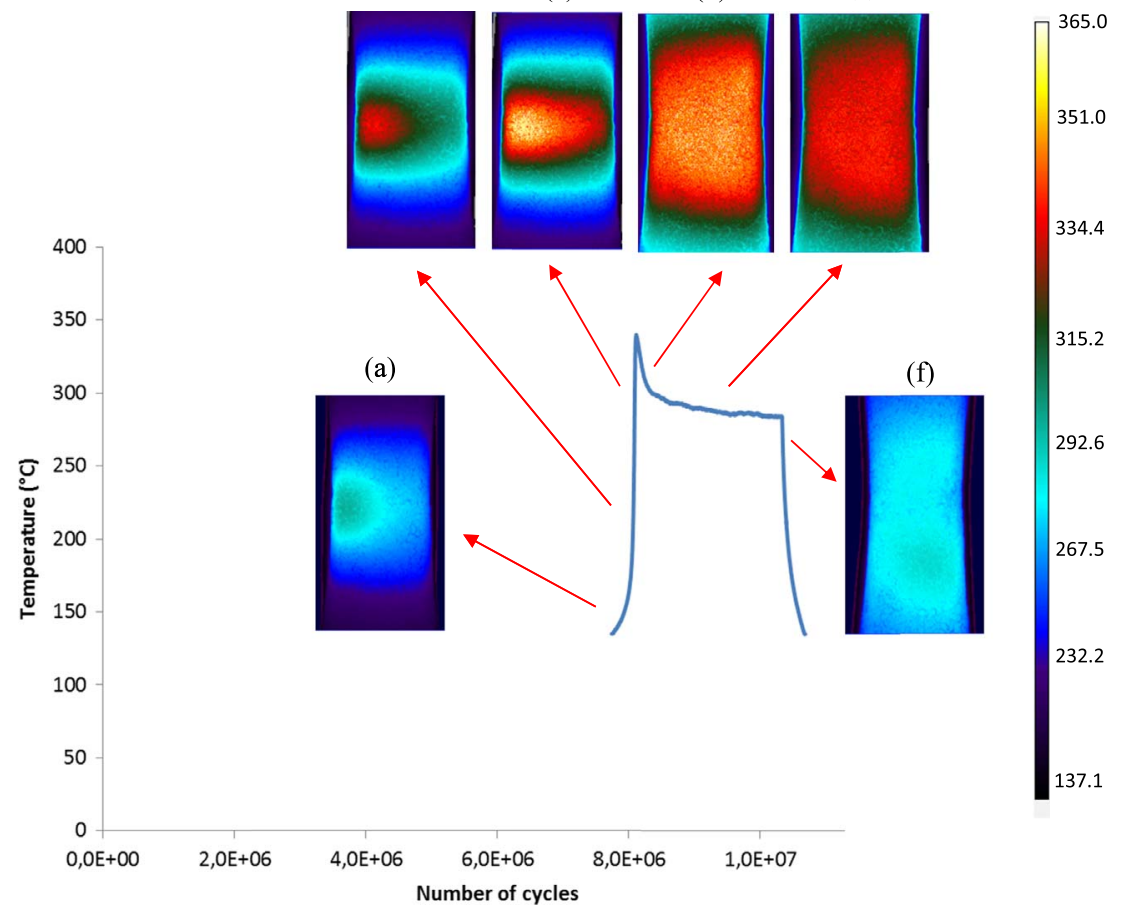

Fig. 8. Temperature fields on specimen surface during cyclic loading and after stopping the test, for $\sigma_{a}=251 \mathrm{MPa}$.

(b)

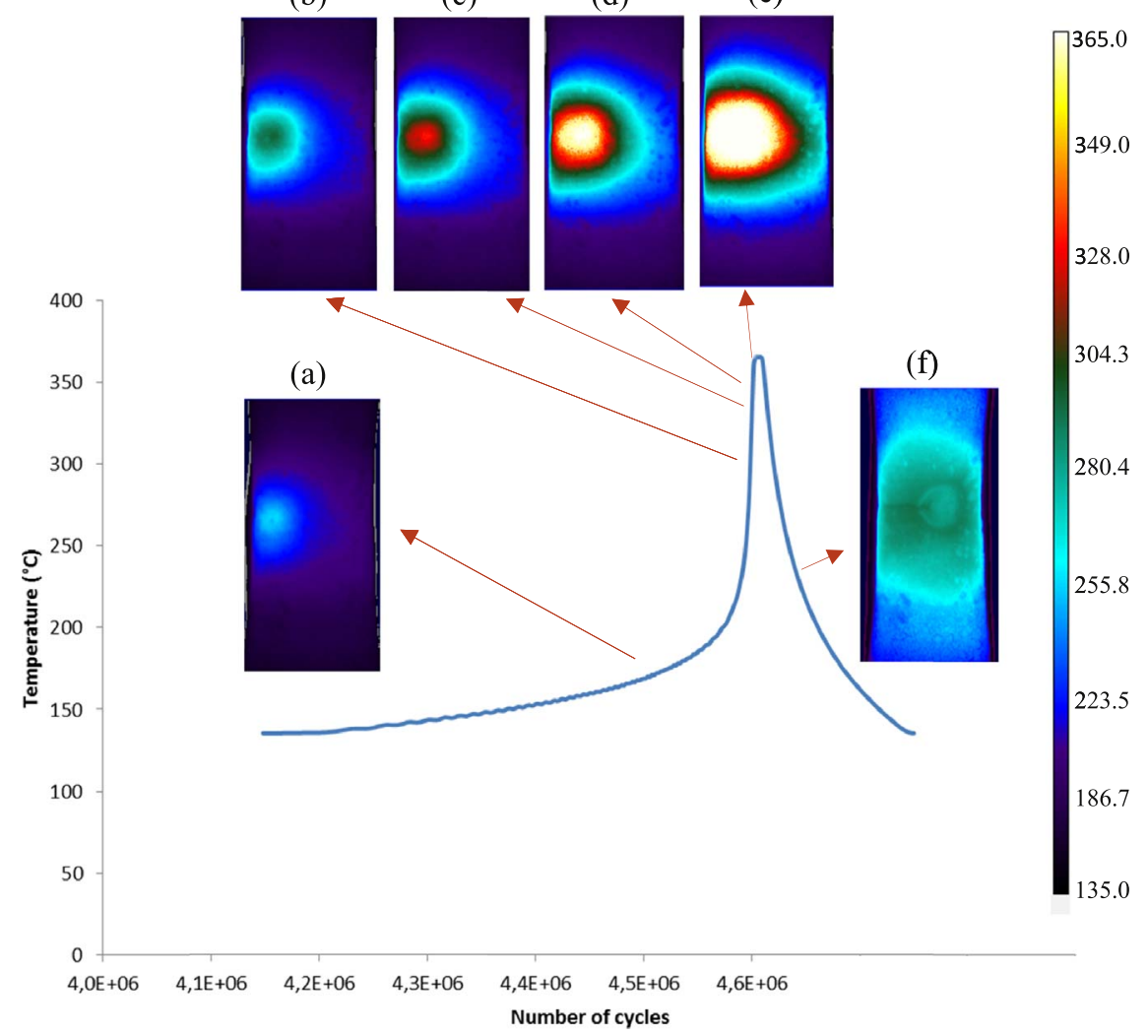

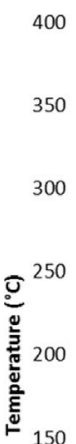

(c)

Fig. 9. Temperature fields on the specimen surface for $\sigma_{a}=330 \mathrm{MPa}$. automatically and the temperature dropped suddenly. After the specimen cooled down, it was possible to observe the temperature distribution around the crack tip (Fig. 9(f)). In Fig. 9(e), the white color means that the temperature exceeded the maximum recordable temperature of the camera $\left(365^{\circ} \mathrm{C}\right)$ for $\sim 0.4 \mathrm{~s}$.

For stress amplitudes corresponding to points $C$ and $D$ in Fig. 6 , the temperature field pattern was the same as in Fig. 7 (no localized dissipative zone was observed). 


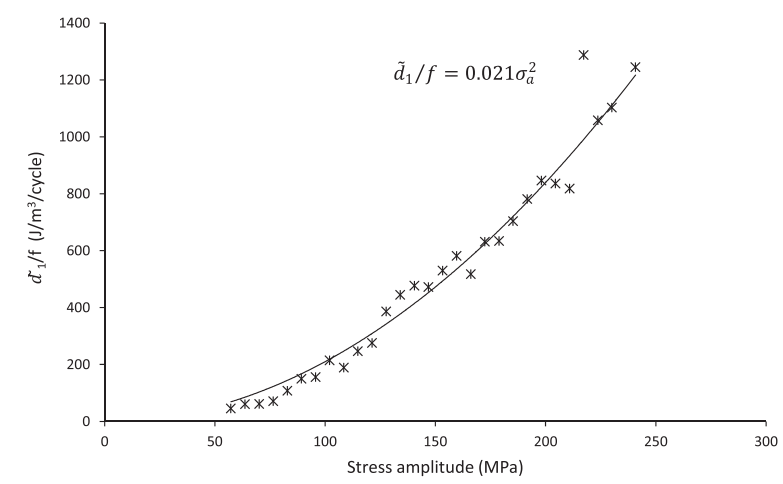

Fig. 10. Mean dissipated energy per cycle versus stress amplitude, for DP600 steel under ultrasonic loading.

\subsection{Heat source estimations}

Temperature variation is not an intrinsic material response as it depends on the material diffusion properties and the thermal boundary conditions. Therefore, some methods have been developed to determine the heat source fields that accompany the temperature variations and these methods consider dissipated energy as a fatigue damage indicator. In other words, the dissipated energy in a unit volume of material is a more promising representation of the material behavior because of its clear physical meaning and its high sensitivity to microstructure evolution $[4,6]$.

In this study, the specific form of heat diffusion equation proposed by Boulanger et al. [22] is used to estimate the intrinsic dissipation from temperature measurements. Assuming there is no coupling between microstructure and temperature and neglecting the convective terms, the heat diffusion equation is written as:

$\rho C \dot{T}-\operatorname{div}(\overrightarrow{\operatorname{kgrad}(T)})=s_{\text {the }}+d_{1}+r$

where $\rho$ is the mass density, $C$ is the specific heat, $\dot{T}$ denotes the time derivative of temperature, $k$ is the conduction coefficient, $s_{\text {the }}$ is the thermoelastic source, $d_{1}$ is the intrinsic heat dissipation and $r$ is the external volume heat supply. For the DP600 steel, $\rho=7800 \mathrm{~kg} / \mathrm{m}^{3}$ and $C=460 \mathrm{~J} / \mathrm{kg} /{ }^{\circ} \mathrm{C}[23]$.

It is assumed that the volume heat source is time independent so it is expressed as:

$r=-k T_{0}$

in which $T_{0}$ is the initial equilibrium temperature. By assuming that the material parameters $\rho, C$ and $k$ are constant and by introducing the temperature increase $\theta=T-T_{0}$, the heat diffusion equation can be rewritten as:

$\rho C \dot{\theta}-k \Delta \theta=s_{\text {the }}+d_{1}$

where $\dot{\theta}$ denotes the time derivative of temperature increase and $\Delta$ is the Laplace operator.

As suggested by Boulanger et al. [22], for symmetric boundary conditions and initial conditions corresponding to a uniform temperature field, it can be assumed that heat losses are linear with respect to the temperature variation, so $k \Delta \theta$ can be approximated by $k \Delta \theta=\rho C \frac{\theta}{\tau}$, where $\tau$ is a time constant describing the thermal exchanges between the specimen and its environment. The heat diffusion equation is rewritten as:

$\rho C \dot{\theta}+\rho C \frac{\theta}{\tau}=s_{\text {the }}+d_{1}$
The thermal boundary conditions are not symmetrical in this case because one end of the specimen is fixed to the horn and the other end is free as discussed by Blanche et al. [15]. However, the thermographic images that were presented in the previous section show that the specimen temperature field is symmetrical for a low stress amplitude. That is why Eq. (4) is considered here.

The time constant $\tau$ can be determined at the end of the test, just after the unloading when there is no applied stress; at this moment, the thermoelastic and intrinsic dissipation heat sources are zero whereas the temperature increase is not null ( $\left.\theta=T-T_{0} \neq 0\right)$. Therefore, the heat equation is reduced to:

$\rho C \dot{\theta}+\rho C \frac{\theta}{\tau}=0$

By solving the above equation, the theoretical relationship for temperature increase is obtained as:

$\theta(t)=\theta_{f} \exp \left(\frac{-t}{\tau}\right)$

where $\theta_{f}$ is the temperature increase that is measured when the loading stops. Thus $\tau$ is estimated by fitting the experimental data with the theoretical evolution of $\theta$.

Because the loading frequency is much higher than the frame rate of the infrared camera $(\sim 100 \mathrm{~Hz})$, it is not possible to measure the instantaneous value of $\theta$, but only its average value can be determined over numerous loading cycles. Therefore, for any variable, by denoting:

$\tilde{u}=\frac{1}{n T_{1}} \int_{t}^{t+n T_{1}} u d t=\frac{f}{n} \int_{t}^{t+T_{1}} u d t$

where $T_{1}$ is the period of the loading, $f$ is the loading frequency and $n$ is the number of cycles, the heat diffusion equation can be rewritten as:

$\rho C \dot{\tilde{\theta}}+\rho C \frac{\tilde{\theta}}{\tau}=\tilde{s}_{\text {the }}+\tilde{d}_{1}$

As stated by Boulanger et al. [22], the sum of the thermoelastic power over one loading cycle is null $\left(\tilde{s}_{\text {the }}=0\right)$, and thus the final form of the heat diffusion equation is obtained:

$\rho C \dot{\tilde{\theta}}+\rho C \frac{\tilde{\theta}}{\tau}=\tilde{d}_{1}$

Therefore, in the stabilized regime, when $\dot{\tilde{\theta}}=0$, the intrinsic dissipation averaged over numerous cycles is determined from Eq. (9) as:

$\rho C \frac{\tilde{\theta}}{\tau}=\tilde{d}_{1}$

The mean dissipated energy per cycle can be obtained as $\tilde{d}_{1} / f$, where $f$ is the loading frequency.

Since at high stress amplitudes, the thermal and mechanical properties of the material can be changed because of the high temperature increase, this formulation was used to measure the dissipated energy per cycle for low stress amplitudes (up to $247 \mathrm{MPa}$ ) for which no abrupt temperature elevation occurred.

Fig. 10 shows the measured dissipated energy per cycle as a function of stress amplitude. A higher stress amplitude yields a higher dissipated energy. Moreover, the dissipated energy per cycle is a quadratic function of stress amplitude.

\section{Discussion}

Several questions should be answered regarding the thermal response of the material under ultrasonic fatigue loading, as 
shown in Fig. 5. What are the heating mechanisms at different ranges of stress amplitude? What is the reason for the substantial increase in temperature at stress amplitudes above $247 \mathrm{MPa}$ ? What is the reason for the subsequent slight decrease in temperature before stabilization for such high stress values? This section will address these questions.

\subsection{Two self-heating regimes}

In general, for materials with a stabilized microstructure, two main heating mechanisms can be considered that result in a temperature increase during fatigue tests $[19,24,25]$ : for low stress amplitudes, below the fatigue limit, microplastic deformation is negligible and the intrinsic dissipation stems from dislocations that move with friction because they interact with the lattice (Peierls-Nabarro landscape) and/or solute atoms. This motion is quasi-recoverable after unloading or fully reversed loading and is labeled as anelasticity from a macroscopic viewpoint. On the contrary, for higher stress amplitudes, microplastic deformation occurs and considerably increases the heat source, which results in high temperature elevations. The critical stress amplitude corresponding to the change in thermal response from the low-stress amplitude regime to the high-stress amplitude regime is associated with the fatigue limit by many authors [1-6]. Guo et al. [6] reported that this change is related to the transition of deformation mechanism from anelasticity to a combination of anelasticity and microplasticity. Munier et al. [5] also evidenced two selfheating regimes. The primary regime was characterized by a slope of 2 when plotting the self-heating-stress amplitude curve using a logarithmic scale (showing a quadratic evolution of the selfheating versus stress amplitude) for all the studied steel grades. For the secondary regime, the slope varied from 6 to 30 depending on the steel grades and was equal to $\sim 13$ for DP600 steel grade. However, they attributed both regimes to microplasticity mechanisms.

In our case, a quadratic evolution of the dissipated energy per cycle versus stress amplitude was found for low stress amplitudes (below $247 \mathrm{MPa}$ ). Above $247 \mathrm{MPa}$, an abnormal thermal response was observed: a strong and localized dissipative zone occurred, which resulted in an abrupt increase in temperature followed by a slight temperature decrease and then temperature stabilization. In the following sections, the thermal response for both cases (stress amplitudes below and above $247 \mathrm{MPa}$ ) is discussed.

\subsection{Material thermal response at low stress amplitudes}

Concerning the dissipated energy measurements (Fig. 10) for

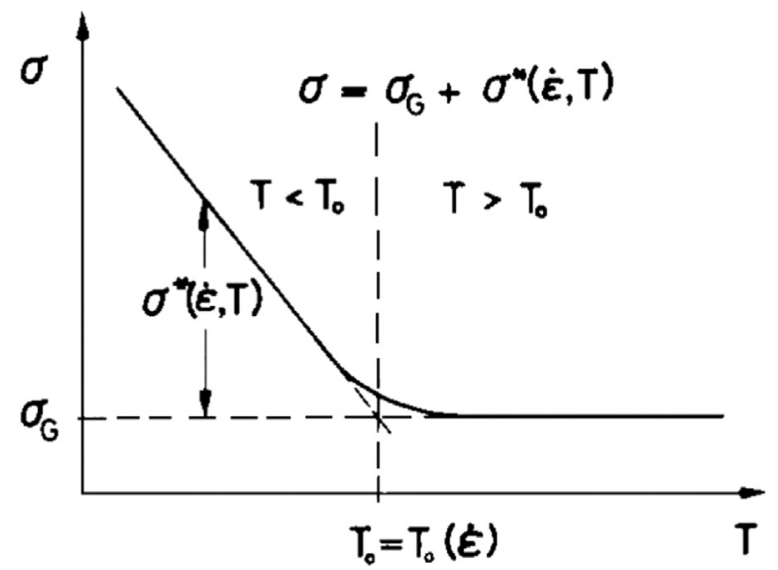

Fig. 11. Schematic diagram of flow stress of bcc metals versus temperature, from [26]. low stress amplitudes ( $\sigma_{a}<247 \mathrm{MPa}$ ), the change in dissipated energy per cycle with increasing stress amplitude is of quadratic form. This result is consistent with the Munier et al. results for the low-frequency fatigue loading $(30 \mathrm{~Hz})$ of DP600 steel [5]. Considering that the dissipated energy results from anelastic or inelastic material behaviors that are characterized by constant properties, we obtain the following expressions for dissipated energy [25]; by assuming a prescribed sinusoidal stress with amplitude $\sigma_{a}$ and a Kelvin-Voigt model (spring and dashpot in parallel), the dissipated energy per cycle for anelastic behavior is [25]:

$\frac{\tilde{d}_{1}}{f}=\frac{1}{f} \frac{2 \eta\left(\pi \sigma_{a}\right)^{2}}{\frac{\mu^{2}}{f^{2}}+4 \pi^{2} \eta^{2}}$

where $\mu$ and $\eta$ are the elastic and viscous moduli, respectively.

For inelastic behavior and a zero mean stress, the dissipated energy per cycle is [25]:

$\frac{\tilde{d}_{1}}{f}=\frac{1}{f} \frac{\sigma_{a}^{2}}{2 \eta}$

In both cases, and considering constant material properties ( $\mu$ and $\eta$ ), the dissipated energy per cycle is a quadratic function of the stress amplitude. In this experimental work, because the dissipated energy per cycle was a quadratic function of the stress amplitude for low stress amplitudes, it can be assumed that the material internal state remained nearly the same during cyclic loading.

In ferritic-martensitic dual-phase steel, as the hardness of martensite is much higher than ferrite, dislocations are assumed to move only in the ferritic phase, which is characterized by a bodycentered cubic (bcc) structure. In bcc metals, the flow stress (or flow behavior) depends strongly on temperature and strain rate at low temperatures. Mughrabi et al. [26] described the temperaturedependent deformation of bcc metals by a schematic diagram as shown in Fig. 11. As this figure shows, two deformation modes can be considered based on a transition temperature $\mathrm{T}_{0}$. In the lowtemperature (or thermally activated) mode $\left(\mathrm{T}<\mathrm{T}_{0}\right)$, the screw dislocations are immobile and the edge dislocations move to-andfro in a non-hardening quasi-recoverable manner. On the other hand, in the athermal mode ( $\left.\mathrm{T}>\mathrm{T}_{0}\right)$, mobilities of the screw and edge dislocations are comparable and screw dislocations can cross slip easily. In this mode, strain localization can occur on slip bands and more energy can be dissipated because of high dislocation mobilities. The transition temperature $\mathrm{T}_{0}$ highly depends on strain rate and can be shifted to higher values at high strain rates. For instance, according to the flow behavior diagram reported by Campbell and Ferguson [27] for a $12 \mathrm{wt} \%$ carbon mild steel, $\mathrm{T}_{0}$ would shift from $25^{\circ} \mathrm{C}$ to $100{ }^{\circ} \mathrm{C}$ by increasing the strain rate from $0.01 \mathrm{~s}^{-1}$ to $1 \mathrm{~s}^{-1}$. For ultrasonic fatigue loadings at low stress amplitudes from 60 to $247 \mathrm{MPa}$, the maximum strain rate ranges from $34 \mathrm{~s}^{-1}$ to $141 \mathrm{~s}^{-1}$. Therefore, for such high strain rates, the transition temperature for the DP600 should be higher than room temperature. As a result, and as suggested by Favier et al. [16] for $\alpha$-iron, the thermally activated mode, which is typical of a bcc structure, prevailed at room temperature for a $20-\mathrm{kHz}$ cyclic loading at low stress amplitudes. As mentioned previously, the dissipated energy probably resulted from the to-and-fro motion of dislocations, which results in slight changes in the material internal state, which is consistent with Eqs. (11) and (12).

\subsection{Material thermal response at high stress amplitudes}

During the ultrasonic fatigue tests, by increasing the stress amplitude successively (Fig. 3), the steady-state temperature of the material under cyclic loading increases. Based on the 
aforementioned concept of transition between the thermally activated regime and the athermal regime, it can be supposed that $100{ }^{\circ} \mathrm{C}$ is a critical steady-state temperature corresponding to $\sigma_{c}=247 \mathrm{MPa}$, above which a transition occurs in the deformation mode. This transition results in a significant increase in dissipated energy per cycle and temperature because of the high mobility of the dislocations in the athermal regime. Because of microstructural and mechanical heterogeneities, the mechanisms associated with the athermal regime operated at one edge of the specimen and spread throughout the specimen width because of thermal diffusion. The transition from the thermally activated regime to the athermal regime can thus be considered as a possible mechanism that is responsible for the significant heating observed for high stress amplitudes (247 MPa $<\sigma_{\mathrm{a}}<330 \mathrm{MPa}$ ). Another hypothesis that can be developed is that the strong heating mechanism is related to the initiation of short cracks and a resulting local plasticity at the crack tips; these short cracks are arrested by microstructural barriers after a small number of cycles. However, further investigations are required to validate these hypotheses.

Another point that should be studied regarding the thermal response of the material is the decrease in temperature before the final saturation for the loading steps that involve an abrupt temperature increase (Curves (b) and (e) in Fig. 5). In general, a temperature decrease during a fatigue loading step can result from a change in heating source [13] or a hardening mechanism in the material which reduces the heat dissipation that is deduced from plasticity. Ranc et al. [13] observed such a decrease in temperature for a martensitic steel containing some residual austenite in the microstructure. In their case, martensitic transformation occurred at the beginning of the fatigue tests and acted as a heat source. When the transformation ended, the dissipation decreased, which resulted in a slight decrease in temperature before saturation. However, in our case, the microstructure of the DP steel was stabilized and no phase transformation occurred. The experimental results show that the decrease is related to the high temperature that the material experiences under ultrasonic fatigue loading at high stress amplitudes. In the athermal regime, the mobilities of screw and edge dislocations are similar and the mechanisms of multiplication of dislocations, such as Frank-Read sources operate much more easily than in the thermally activated regime. This leads to a pronounced cyclic hardening [28]. Therefore, the slight decrease in temperature before stabilization most likely arises from a hardening mechanism that is related to the multiplication of dislocations that occurred in the material.

According to the results reported by Ekrami [29], for dualphase steels with different morphologies, the yield and ultimate tensile strengths increase with increasing testing temperature up to $\sim 450{ }^{\circ} \mathrm{C}$ and then decrease at higher temperatures. Up to $450{ }^{\circ} \mathrm{C}$, they observed clear serrations on the stress-strain curve. The serrated yielding indicated the occurrence of dynamic strain aging that affected material hardening. In iron-based alloys (bcc metals), this phenomenon is attributed to elastic interactions of glide dislocations with diffusing solute nitrogen and carbon atoms during deformation at high temperature [30]. During cyclic loading, dynamic strain aging that results in a strong increase in stress amplitude was also observed [28,31].

In our case, as shown in Fig. 5, for $\sigma_{a}=251 \mathrm{MPa}$ the maximum temperature was $\sim 350^{\circ} \mathrm{C}$ immediately before the slight decrease in temperature. Therefore, based on the aforementioned concepts, at this temperature, because of the multiplication of dislocation and dynamic strain aging, the material was work-hardened, and consequently, the plastic dissipation decreased, which resulted in a decrease in temperature before saturation. In addition, with increasing temperature, the annihilation rate of dislocation increases while the multiplication rate remains approximately constant [26]. These competitive hardening-softening mechanisms led to a final saturation in temperature.

Afterwards, when the specimen cooled down and was loaded in the next loading step at higher stress amplitudes, the temperature elevation decreased (Points $C$ and $D$ in Fig. 6); because the material was hardened in the previous step. Finally, at the next loading steps, thanks to an increase in stress amplitude, large dislocation motion occurred again in localized zones producing strong intrinsic dissipation and, once more, large temperature elevations.

\section{Conclusions}

The thermal response of DP600 dual-phase steel was studied under ultrasonic fatigue loading, and an abnormal temperature evolution was observed at stress amplitudes above $247 \mathrm{MPa}$. Two deformation regimes were distinguished and discussed based on the transition between the thermally activated deformation mode and the athermal deformation mode for the ferrite phase.

- Below $247 \mathrm{MPa}$, a quadratic evolution of the dissipated energy per cycle as a function of stress amplitude was determined. The to-and-fro glide of the edge dislocations was considered to be the main dissipative mechanism. This motion is quasi-recoverable and leaves a quasi-constant dislocation structure (no cyclic hardening).

- Above $247 \mathrm{MPa}$, a strong increase in temperature was observed as a consequence of the expansion of strong dissipative zones throughout the specimen width. The temperature decreased slightly to a more or less steady-state during cycling. The presence of strong dissipative zones was attributed to the fact that the transition temperature between the thermally activated deformation mode and the athermal deformation mode was reached because of self-heating. Therefore, the dislocation mobility increased strongly leading to strong dissipated energy in those zones. The higher mobility of dislocations also resulted in a multiplication of dislocations and cyclic hardening. At $\sim 300$ $350{ }^{\circ} \mathrm{C}$, dynamic strain aging was assumed to operate as an extra hardening mechanism.

\section{References}

[1] C.E. Stromeyer, The determination of fatigue limits under alternating stress conditions, Proc. R. Soc. Lond. A 90 (1914) 411-425.

[2] M.P. Luong, Fatigue limit evaluation of metals using an infrared thermographic technique, Mech. Mater. 28 (1998) 155-163.

[3] B. Yang, P.K. Liaw, H. Wang, L. Jiang, J.Y. Huang, R.C. Kuo, J.G. Huang, Thermographic investigation of the fatigue behavior of reactor pressure vessel steels, Mater. Sci. Eng.: A 314 (2001) 131-139.

[4] C. Doudard, S. Calloch, F. Hild, S. Roux, Identification of heat source fields from infrared thermography: Determination of 'self-heating' in a dual-phase steel by using a dog bone sample, Mech. Mater. 42 (2010) 55-62.

[5] R. Munier, C. Doudard, S. Calloch, B. Weber, Determination of high cycle fatigue properties of a wide range of steel sheet grades from self-heating measurements, Int. J. Fatigue 63 (2014) 46-61.

[6] Q. Guo, X. Guo, J. Fan, R. Syed, C. Wu, An energy method for rapid evaluation of high-cycle fatigue parameters based on intrinsic dissipation, Int. J. Fatigue 80 (2015) 136-144.

[7] C. Bathias, Piezoelectric fatigue testing machines and devices, Int. J. Fatigue 28 (2006) 1438-1445.

[8] S. Stanzl-Tschegg, Very high cycle fatigue measuring techniques, Int. J. Fatigue 60 (2014) 2-17.

[9] C. Bathias, Coupling effect of plasticity, thermal dissipation and metallurgical stability in ultrasonic fatigue, Int. J. Fatigue 60 (2014) 18-22.

[10] D. Krewerth, A. Weidner, H. Biermann, Application of in situ thermography for evaluating the high-cycle and very high-cycle fatigue behaviour of cast aluminium alloy AlSi7Mg (T6), Ultrasonics 53 (2013) 1441-1449.

[11] H. Xue, D. Wagner, N. Ranc, E. Bayraktar, Thermographic analysis in ultrasonic fatigue tests, Fatigue Fract. Eng. Mater. Struct. 29 (2006) 573-580.

[12] D. Wagner, N. Ranc, C. Bathias, P.C. Paris, Fatigue crack initiation detection by an infrared thermography method, Fatigue Fract. Eng. Mater. Struct. 33 (2009) 
$12-21$.

[13] N. Ranc, D. Wagner, P.C. Paris, Study of thermal effects associated with crack propagation during very high cycle fatigue tests, Acta Mater. 56 (2008) 4012-4021.

[14] X.G. Wang, V. Crupi, C. Jiang, E. Guglielmino, Quantitative Thermographic Methodology for fatigue life assessment in a multiscale energy dissipation framework, Int. J. Fatigue 81 (2015) 249-256.

[15] A. Blanche, A. Chrysochoos, N. Ranc, V. Favier, Dissipation assessments during dynamic very high cycle fatigue tests, Exp. Mech. 55 (2015) 699-709.

[16] V. Favier, A. Blanche, C. Wang, N.L. Phung, N. Ranc, D. Wagner, C. Bathias, A. Chrysochoos, H. Mughrabi, Very high cycle fatigue for single phase ductile materials: comparison between $\alpha$-iron, copper and $\alpha$-brass polycrystals, Int. J. Fatigue (2016), http://dx.doi.org/10.1016/j.ijfatigue.2016.05.034.

[17] Z.Y. Huang, Q.Y. Wang, D. Wagner, C. Bathias, A very high cycle fatigue therma dissipation investigation for titanium alloy TC4, Mater. Sci. Eng.: A 600 (2014) 153-158.

[18] Z.Y. Huang, Q.Y. Wang, D. Wagner, C. Bathias, J.L. Chaboche, A rapid scatter prediction method for very high cycle fatigue, Fatigue Fract. Eng. Mater. Struct. 36 (2012) 462-468.

[19] C. Mareau, V. Favier, B. Weber, André Galtier, M. Berveiller, Micromechanical modeling of the interactions between the microstructure and the dissipative deformation mechanisms in steels under cyclic loading, Int. J. Plast. 32-33 (2012) 106-120.

[20] N. Ranc, V. Favier, B. Munier, F. Vales, G. Thoquenne, F. Lefebvre, Thermal response of C45 steel in high and very high cycle fatigue, Procedia Eng. 133 (2015) 265-271.

[21] Z. Huang, N. Ranc, D. Wagner, Dislocations gliding study by IR thermography in C-Mn steels with different solute atoms content in the gigacycle fatigue domain, Key Eng. Mater. 664 (2016) 177-187.

[22] T. Boulanger, A. Chrysochoos, A. Mabru, A. Galtier, Calorimetric analysis of dissipative and thermoelastic effects associated with the fatigue behavior of steels, Int. J. Fatigue 26 (2004), 221-219.

[23] A. Chrysochoos, B. Berthel, F. Latourte, S. Pagano, B. Wattrisse, B. Weber, Local energy approach to steel fatigue, Strain 44 (2008) 327-334.

[24] R. De Finis, D. Palumbo, F. Ancona, U. Galietti, Fatigue limit evaluation of various martensitic stainless steels with new robust thermographic data analysis, Int. J. Fatigue 74 (2015) 88-96.

[25] C. Mareau, V. Favier, B. Weber, A. Galtier, Influence of the free surface and the mean stress on the heat dissipation in steels under cyclic loading, Int. J. Fatigue 31 (2009) 1407-1412.

[26] H. Mughrabi, K. Herz, X. Stark, Cyclic deformation and fatigue behavior of $\alpha$ iron mono- and polycrystals, Int. J. Fract. 17 (1981) 193-220.

[27] J.D. Campbell, W.G. Ferguson, The temperature and strain rate dependence of the shear strength of mild steel, Philos. Mag. 21 (1970) 63-82.

[28] C. Sommer, H. Mughrabi, D. Lochner, Influence of temperature and carbon content on the cyclic deformation and fatigue behaviour of alpha-iron. Part I: cyclic deformation and stress-behaviour, Acta Mater. 46 (1998) 1527-1536.

[29] A. Ekrami, High temperature mechanical properties of dual phase steels, Mater. Lett. 59 (2005) 2070-2074.

[30] G. Schoeck, The Portevin-Le Chatelier effect. A kinetic theory, Acta Metall. 32 (1984) 1229-1234.

[31] K. Pohl, P. Mayr, E. Macherauch, Cyclic deformation behavior of a low carbon steel in the temperature range between room temperature and $850 \mathrm{~K}$, Int. J. Fract. 17 (1981) 221-233. 